Original Article

\title{
Effects of two different mobilization techniques on pain, range of motion and functional disability in patients with adhesive capsulitis: a comparative study
}

\author{
Surabhi Agarwal, BPT, MPT ${ }^{1}$, Shahid Raza, MPT ${ }^{1)^{*}}$, JAmal Ali Moiz, MPT ${ }^{1}$, \\ Shahnawaz Anwer, MPT ${ }^{2,3)}$, Ahmad H. Alghadir, MS, PhD, PT ${ }^{2}$ ) \\ 1) Centre for Physiotherapy and Rehabilitation Sciences: Jamia Millia Islamia, New Delhi 110025, India \\ 2) Rehabilitation Research Chair, College of Applied Medical Sciences, King Saud University, Saudi Arabia \\ 3) Dr. D. Y. Patil College of Physiotherapy, Dr. D. Y. Patil Vidyapeeth, India
}

\begin{abstract}
Purpose] This study aimed to compare the effects of two different mobilization techniques in the management of patients with adhesive capsulitis. [Subjects and Methods] Thirty non-diabetic men and women with adhesive capsulitis were randomly allocated to the reverse distraction group $(\mathrm{n}=15)$ or Kaltenborn group $(\mathrm{n}=15)$. The reverse distraction technique and Kaltenborn's caudal and posterior glides (grades III and IV) were applied 10-15 times along with conventional physical therapy for 18 treatment sessions in 6 weeks. Pain was measured with a visual analog scale, abduction and external rotation range of motion with goniometry, hand behind back reach with inch tape, and functional disability with the Flexilevel scale of shoulder function before and after the treatment. [Results] Although all the variables improved significantly in both groups after 18 intervention sessions, reverse distraction was significantly better than Kaltenborn's caudal and posterior glides in decreasing pain and improving abduction range of motion and functional scores. [Conclusion] This study supports the clinical use of reverse distraction as an alternative to conventional mobilization techniques to decrease pain and improve range of motion and functional scores in patients with adhesive capsulitis.

Key words: Reverse distraction technique, Kaltenborn's glide, Adhesive capsulitis
\end{abstract}

(This article was submitted Jun. 19, 2016, and was accepted Aug. 9, 2016)

\section{INTRODUCTION}

Adhesive capsulitis can be defined as a common condition characterized by insidious and gradual inflammation of the glenohumeral joint capsule leading to its contracture and thus resulting in stiffness and loss of shoulder mobility ${ }^{1)}$. The prevalence rate has been reported to be $2-5.3 \%^{2-5}$, with individuals in the age group between 40 to 70 years commonly affected ${ }^{6}$. Secondary adhesive capsulitis is a result of a pre-existing shoulder condition such as dislocation, humeral fracture, and osteoarthritis or a neurological condition leading to muscular imbalances. The prevalence of secondary adhesive capsulitis related to type 2 diabetes and thyroid disease is between $4.3 \%$ and $38 \%{ }^{7}$.

According to the literature, inflammatory changes in the capsule and synovium of the glenohumeral joint are responsible for contracture of the capsule ${ }^{8-10}$. This contracture brings the humeral head close to the glenoid fossa ${ }^{11)}$. The overall active and passive range of motion (ROM) of the shoulder joint in the capsular pattern is reduced, with the largest changes in ROM observed, in descending order, in external rotation, abduction, and internal rotation ${ }^{12)}$. These limitations in shoulder motion, which are referred to as frozen shoulder, greatly affect patient's activities of daily living ${ }^{13)}$.

*Corresponding author. Shahid Raza (E-mail: mraza1@jmi.ac.in)

(C2016 The Society of Physical Therapy Science. Published by IPEC Inc.

This is an open-access article distributed under the terms of the Creative Commons Attribution Non-Commercial No Derivatives (by-nc-nd) License $<$ http://creativecommons.org/licenses/by-nc-nd/4.0/>. 
Although this condition is found to be self-limiting and gradually resolves within 3 years in most patients ${ }^{14)}$, the course of the disease can extended beyond 3 years in some cases ${ }^{15)}$. This results in a greater emotional and economic distress, with the patient suffering from long-term pain and limited shoulder movement ${ }^{16)}$.

Joint mobilization, including Maitland's oscillatory techniques and Kaltenborn's sustained stretch technique, is used clinically to treat adhesive capsulitis. The purpose of the mobilizing exercise therapy for a frozen shoulder is primarily to increase shoulder movement by stretching the glenohumeral joint capsule ${ }^{17)}$. Research has shown that Maitland's and Kaltenborn's techniques are similarly effective in reducing pain and improving ROM in adhesive capsulitis patients.

These techniques mobilize the glenohumeral joint while keeping the scapula fixed relative to the thorax and glenohumeral joint ${ }^{18)}$. To improve the external rotation ROM of the shoulder, glenohumeral anterior glide mobilization has been used by physical therapists, which follows the principle of the "convex on concave rule" of joint movement. Harryman et al. ${ }^{19)}$ postulated the capsular constraint mechanism, which contrasts the convex on concave theory. Some researchers have found that the external and internal rotation ROM increases with posterior gliding manipulation of the shoulder ${ }^{20,21)}$. Thus, according to Roubal et al. ${ }^{20)}$, caudal glide increased flexion and abduction ROM. Johnson et al. ${ }^{22}$ ) conducted a randomized control trial in 20 patients with adhesive capsulitis, which compared anterior and posterior glide mobilization with lateral traction of the glenohumeral joint. It was concluded that an increase in external rotation ROM can be achieved by Kaltenborn's grade III posterior glide mobilization. Sarkari et al. ${ }^{23)}$ also suggested that glenohumeral abduction ROM in these patients can be improved by end-range caudal and posterior glide mobilization.

Stenvers ${ }^{17}$ ) stated that the glenohumeral joint capsule can be stretched by fixing the scapula and moving the humerus or by fixing the humerus and moving the scapula. In terms of biomechanics, it was suggested that during the movement of the humerus with respect to the scapula, the scapula is eventually fixed, but in an unnatural position. Furthermore, movement of the humerus causes pain. Because of this pain, it is not possible to exert force on the glenohumeral joint capsule. For this reason, movement of the humerus with respect to the fixed scapula, as implemented in traditional gliding techniques, is not an effective mobilization method. Movement of the scapula with respect to the humerus is a better mobilization method because it stretches the capsule directly and is painless. Vermeulen et al. ${ }^{24)}$ used this reverse distraction technique on the glenohumeral joint at different angles of abduction and flexion at end ranges with a purpose of stretching the contracted periarticular structures in patients with adhesive capsulitis. Their results showed an increase in mean capacity of the glenohumeral joint capsule, improved active mobility for flexion and external rotation, and improvement in shoulder function after 3 months of treatment.

Although both manual shoulder mobilization techniques are widely used in the treatment of adhesive capsulitis, they are different in terms of therapeutic implementation. Thus, Kaltenborn's caudal glide and posterior glide techniques involve lateral distraction of the humeral head followed by caudal and posterior stretch mobilization of the glenohumeral joint, with the patient in the supine position with the scapula stabilized, whereas the reverse distraction technique involves glenohumeral distraction at varying angles of abduction and flexion along with lateral border scapula mobilization via medial and downward rotation, with the patient in the lateral position.

Vermeulen et al. ${ }^{25}$ ) used the reverse distraction technique in combination with other oscillatory glides to prove that high-grade mobilization (Maitland grades III and IV) techniques are more effective than low-grade mobilization (grade I) techniques in the treatment of adhesive capsulitis. The studies mentioned above used the reverse distraction technique (involving movement of the scapula relative to the thorax, with the glenohumeral joint distracted) in combination with other mobilization techniques; at present, there is no evidence proving that reverse distraction alone can be effective in the management of adhesive capsulitis. Thus, the aim of the present study was to compare the efficiency of the reverse distraction technique with that of traditionally used gliding techniques (posterior and caudal glides) in improving joint mobility and alleviating pain and disability in patients with adhesive capsulitis.

\section{SUBJECTS AND METHODS}

Initially, 43 patients were evaluated at a physiotherapy outpatient department, Jamia Millia Islamia, New Delhi, India. Subjects were included if they had unilateral idiopathic or primary adhesive capsulitis, were between 40 and 70 years old, and had pain, stiffness, and limitation of passive shoulder lateral rotation, abduction, and internal rotation of more than $50 \%$ compared with the opposite side for at least 3 months. The exclusion criteria were presence of neurological disorders (e.g., stroke, Parkinson's disease) leading to deficiency of shoulder muscles activity, diabetes, severe trauma related to painful stiff shoulder, bony changes or osteoarthritis of the affected shoulder on radiographs, and previous surgeries and manipulation under anesthesia of the affected shoulder. Ethical approval was granted by the institutional human ethical committee, and the subjects who agreed to participate signed written informed consent in accordance with the declaration of Helsinki. Instructions were given to use their effected arm in activities of daily living within pain-free limits and to avoid activities demanding resisted movements (e.g., gardening, vacuuming, sawing, pulling, pushing, stiff door opening or closing) or lifting heavy weights. Patients were asked about their occupation, dominant arm, affected arm, time when they started to experience the discomfort when moving the arm, and any minor or trivial injury preceding the onset of the symptoms.

Thirty patients that fulfilled the inclusion and exclusion criteria were recruited and randomly allocated to one of two treatment groups (15 patients in each): a) reverse distraction group and b) Kaltenborn's caudal and posterior glide mobilization 
group. Two subjects, one from each group, left the study within two weeks of the intervention. Assessments were made at baseline (before the first treatment session) and after 18 treatment sessions ( 6 weeks). All the measurements were performed by the same therapist (SA).

For assessing pain during shoulder joint movement, subjects used a visual analogue scale (VAS) ${ }^{12)}$ consisting of a $10-\mathrm{cm}$ vertical line, with one end corresponding to no pain during shoulder movement and the other end to maximal pain. The reliability of this test was reported to be 0.94 for literate and 0.71 for illiterate patients ${ }^{26}$. Criterion validity has not been evaluated because of the absence of a gold standard for pain measurement ${ }^{27)}$.

In the present study, active and passive abduction (in the frontal plane) and external rotation (with the arm at 0 degrees of abduction) ROM was measured with a conventional goniometer as per the guidelines given by the American Academy of Orthopaedic Surgeons ${ }^{28}$. Goniometric measurements are highly reliable provided measurements are conducted by same therapist $^{29)}$ (test-retest reliability: 0.94-0.98) ${ }^{12,24,29)}$.

Hand behind back $(\mathrm{HBB})$ reach was measured in centimeters using inch tape with subjects in the standing position. They were instructed to achieve the maximum HBB reach position by moving their affected extremity upwards and towards the midline with the thumb extended. In this position, the distance between the L5 spinous process and the radial styloid process was measured. The radial styloid process was used to decrease the measurement error related to movements at the wrist and thumb joints ${ }^{30}$. If a patient was not able to reach the posterior inferior iliac spine (considered as the starting point) with his/ her hand, the distance (in centimeters) was considered negative. If the hand could not reach the midline, measurements were taken by drawing a horizontal line from the reached position to the central level ${ }^{31)}$. The distance between the L5 and C7 spinous processes was also measured to normalize the distance between the L5 spinous process and the radial styloid process, thereby eliminating differences due to variations in height ${ }^{32}$.

Functional disability was measured with a self-administered, shoulder-specific, fixed-item index, Flexilevel score of shoulder dysfunction (FLEX-SF). FLEX-SF measures three levels of function, with each item scoring the level of function as low, medium, or high. Subjects responded only to the items that reflected their functional level. Scores ranged from 0 , indicating the most limited function, to 60 , signifying no functional limits. This scale has been reported to have a high reliability $(\mathrm{ICC}=0.90)$ and validity (responsiveness index $=1.2)^{33)}$.

In the reverse distraction group, patients were asked to lie on their unaffected side at the edge of a plinth. The upper hand of the therapist was placed on patient's humeral head just below the acromion for applying glenohumeral distraction at various angles of abduction and flexion ${ }^{24)}$. The upper hand maintained the required angle of abduction or flexion, whereas the lower hand was placed on the lateral border of the scapula for mobilizing it in medial and downward rotation ${ }^{17,24)}$. There were 10-15 repetitions per each of 3 treatment sessions administered each week; a total of 18 sessions were performed during 6 weeks. After each session of mobilization, movements within the active, pain-free ROM were encouraged.

In the Kaltenborn group, stretch mobilization techniques (glide) were used ${ }^{34}$, which can be characterized as low-rate, low-amplitude techniques with sustained loading of restricting tissue at the end ranges of abduction and/or external rotation with a uniform, gliding movement. Each Kaltenborn grade III glide ("after the slack of the joint has been taken up") was given for 1 minute for a total of 15 minutes of sustained stretch, without giving any oscillatory glides.

For posterior glide, lateral humeral distraction was maintained with abduction in the end range, with the patient in the supine lying position and the scapula stabilized. The progression arm was put at the flexion end range, and posterior stretch mobilization was performed along with lateral humeral distraction.

For caudal glide, the patient was placed in the supine position with the scapula stabilized. Lateral humeral distraction was maintained, and caudal stretch mobilization was done in the resting position of the shoulder joint. For progression of the caudal glide, lateral humeral distraction was followed by caudal stretch mobilization. Subjects were treated in 3 sessions per week for 6 weeks. After each session of mobilization, movements within the active, pain-free ROM were encouraged. Both mobilization techniques were administered by the same therapist (SA) to minimize the inter-therapist variability.

The conventional physical therapy treatment for adhesive capsulitis was administered in both groups. A hot pack was applied as a superficial heating modality at the shoulder joint for 15-20 minutes. For relaxation of the muscles around the shoulder, Codman's pendular exercises were performed ${ }^{25}, 35$. Four-direction shoulder stretching in forward elevation, external rotation, horizontal adduction, and internal rotation was performed ${ }^{36)}$. Stretches were performed 2-3 times a day and maintained for $1-5$ seconds in a comfortable range ${ }^{37}$ ).

Experimental results were statistically analyzed using SPSS 21, Windows version. The Shapiro-Wilk test was applied to assess the normal distribution of scores. All the data were normal, except VAS and HBB reach. Accordingly, we logtransformed the VAS scores. Since HBB reach data could not be normalized because of the presence of negative values, a non-parametric test was applied for analysis. For between-group comparison of demographic characteristics at baseline, the independent t-test (age, height, and body mass), $\chi^{2}$ test (gender, dominant arm, side of affected arm, occupation, and any previous minor injury to the affected shoulder recalled by the subject), and Mann-Whitney U test (duration of symptoms) were employed. Shoulder abduction and external rotation active and passive ROM, VAS scores for pain, HBB for internal rotation, and FLEX-SF scores at baseline were analyzed using the independent t-test.

VAS, abduction and external rotation active and passive ROM, and FLEX SF score were measured at baseline and at the end of the 6-week therapy (18 treatment sessions) using the dependent t-test and compared between the groups using the independent t-test. Changes in HBB reach were assessed using the Wilcoxon signed rank test, and between-group changes were analyzed using the Mann-Whitney $U$ test. The level of significance was set at $\mathrm{p}<0.05$. 


\section{RESULTS}

At baseline, the VAS scores of the two groups were similar (Table 1). A comparison of the VAS pain scores measured at baseline and during the final treatment session in both groups revealed that the reverse distraction technique decreased pain significantly compared to Kaltenborn's mobilization $(\mathrm{p}<0.001)$ (Table 2$)$. A significant $(p<0.001)$ decrease in pain by the end of the treatment was observed in both groups.

No significant difference between the groups was observed at baseline in abduction and external rotation active and

Table 1. Comparison of demographic characteristics of patients in the reverse distraction and Kaltenborn groups

\begin{tabular}{|c|c|c|}
\hline Subject characteristics & $\begin{array}{c}\text { Reverse distraction group } \\
(\mathrm{Mean} \pm \mathrm{SD}) / \text { median (min, } \max )\end{array}$ & $\begin{array}{c}\text { Kaltenborn group } \\
(\text { Mean } \pm \mathrm{SD}) / \text { median (min, } \max )\end{array}$ \\
\hline Age $\left(\right.$ years) ${ }^{t}$ & $48.7 \pm 6.4^{\mathrm{a}}$ & $52.5 \pm 9.6^{\mathrm{a}}$ \\
\hline Weight $(\mathrm{kg})^{\mathrm{t}}$ & $69.7 \pm 8.7^{\mathrm{a}}$ & $71.6 \pm 6.8^{\mathrm{a}}$ \\
\hline Height $(\mathrm{cm})^{\mathrm{t}}$ & $162.7 \pm 8.1^{\mathrm{a}}$ & $162.5 \pm 9.1^{\mathrm{a}}$ \\
\hline BMI $\left(\mathrm{kg} / \mathrm{mt}^{2}\right)^{\mathrm{t}}$ & $26.2 \pm 1.6^{\mathrm{a}}$ & $27.2 \pm 3.1^{\mathrm{a}}$ \\
\hline Gender (females, males) ${ }^{\mathrm{c}}$ & 7,7 & 6,8 \\
\hline Dominant $\operatorname{arm}(\mathrm{n})^{\mathrm{c}}$ * & 13 right & 12 right \\
\hline Affected $\operatorname{arm}(n)^{\mathrm{c} *}$ & 12 right, 2 left & 11 right, 3 left \\
\hline Occupation $(\mathrm{n})^{\mathrm{c} *}$ & 11 sedentary, 3 manual & 10 sedentary, 4 manual \\
\hline Minor injury recalled $\mathrm{c}^{*}$ & 2 yes, 12 no & 4 yes, 10 no \\
\hline Symptoms duration (Months) ${ }^{\mathrm{u}}$ & $4.6(2.9,6.2)^{\mathrm{b}}$ & $5(3,7)$ \\
\hline VAS $^{t}$ & $8.1 \pm 0.7^{\mathrm{a}}$ & $7.4 \pm 1.1^{\mathrm{a}}$ \\
\hline Shoulder Abd. AROM $\left({ }^{\circ}\right)^{t}$ & $93.5 \pm 9.8^{\text {a }}$ & $88.4 \pm 9.7^{\mathrm{a}}$ \\
\hline Shoulder Abd. PROM $\left({ }^{\circ}\right)^{t}$ & $99.3 \pm 10.0^{\mathrm{a}}$ & $96.0 \pm 10.6^{\mathrm{a}}$ \\
\hline Shoulder E.R. AROM $\left({ }^{\circ}\right)^{t}$ & $25.8 \pm 11.5^{\mathrm{a}}$ & $28.7 \pm 12.5^{\mathrm{a}}$ \\
\hline Shoulder E.R. PROM $\left({ }^{\circ}\right)^{t}$ & $31.2 \pm 11.2^{\mathrm{a}}$ & $36.5 \pm 12.3^{\mathrm{a}}$ \\
\hline $\operatorname{HBB}(\%)^{\mathrm{u}}$ & $6.7^{b}$ & $8.1^{\mathrm{b}}$ \\
\hline FLEX-SF score ${ }^{t}$ & $36.0 \pm 8.5^{\mathrm{a}}$ & $36.6 \pm 8.1^{\mathrm{a}}$ \\
\hline
\end{tabular}

VAS: visual analogue scale; Abd: abduction; AROM: active range of motion; PROM: passive range of motion; ER: external rotation; HBB: hand behind back reach; FLEX-SF: flexillevel scale of shoulder function; BMI: body mass index; ${ }^{\mathrm{a}}$ mean $\pm \mathrm{SD} ;{ }^{\mathrm{b}}$ median; ${ }^{\mathrm{c}} \chi^{2}$ test; ${ }^{\mathrm{t}}$ Independent t-test; ${ }^{\mathrm{u} M a n n-W h i t n e y ~} \mathrm{U}$ test; *Significant at $<0.05 ;\left(^{\circ}\right)$ : degree; HBB (\%): normalized HBB values were calculated using the following formula and median reported:

$\operatorname{HBB}(\%)=\frac{\text { distance from L5 to hand behind back reach }}{\text { distance from L5 to } \mathrm{C} 7} \times 100$

Table 2. Comparison of outcome variables between the reverse distraction and Kaltenborn groups using the independent t-test/Mann-Whitney U test

\begin{tabular}{lcc}
\hline Variables & $\begin{array}{c}\text { Reverse distraction } \\
\text { mean } \pm \mathrm{SD} / \text { median }\end{array}$ & $\begin{array}{c}\text { Kaltenborn } \\
\text { mean } \pm \mathrm{SD} / \text { median }\end{array}$ \\
\hline VAS $(\mathrm{cm})^{\mathrm{t} *}$ & $2.5 \pm 0.9^{\mathrm{a}}$ & $5.5 \pm 1.3^{\mathrm{a}}$ \\
Abduction AROM $\left({ }^{\circ}\right)^{\mathrm{t}^{*}}$ & $165.7 \pm 8.4^{\mathrm{a}}$ & $139.4 \pm 13.5^{\mathrm{a}}$ \\
Abduction PROM $\left({ }^{\circ}\right)^{\mathrm{t}^{*}}$ & $171.9 \pm 7.7^{\mathrm{a}}$ & $146.4 \pm 12.6^{\mathrm{a}}$ \\
E.R. AROM $\left({ }^{\circ}\right)^{\mathrm{t}}$ & $54.5 \pm 13.0^{\mathrm{a}}$ & $49.4 \pm 12.2^{\mathrm{a}}$ \\
E.R. PROM $\left({ }^{\circ}\right)^{\mathrm{t}}$ & $60.0 \pm 11.3^{\mathrm{a}}$ & $57.6 \pm 11.7^{\mathrm{a}}$ \\
HBB $(\%)^{\mathrm{u}}$ & $12.9^{\mathrm{b}}$ & $10.9^{\mathrm{b}}$ \\
FLEX-SF score & $53.1 \pm 3.5^{\mathrm{a}}$ & $50.0 \pm 3.3^{\mathrm{a}}$ \\
\hline
\end{tabular}

VAS: visual analogue scale; AROM: active range of motion; $\left({ }^{\circ}\right)$ : degrees; PROM: passive range of motion; ER: external rotation; HBB: hand behind back reach; FLEX-SF: flexillevel scale of shoulder function; ${ }^{\mathrm{a}}$ mean $\pm \mathrm{SD}$; ${ }^{\mathrm{m}}$ median; 'Independent t-test; ${ }^{\mathrm{u} M a n n-W h i t n e y ~ U}$ test; *significant at $<0.05$. HBB (\%) was calculated using the following formula:

$\operatorname{HBB}(\%)=\frac{\text { distance from } \mathrm{L} 5 \text { to hand behind back reach }}{\text { distance from L5 to } \mathrm{C} 7} \times 100$ 
passive mobility $(\mathrm{p}>0.05)$ (Table 1$)$. Although abduction active and passive ROM increased significantly $(\mathrm{p}<0.01)$ in the reverse distraction group compared to the Kaltenborn group, the results were not significant for external rotation active ROM $(p=0.300)$ and passive ROM $(p=0.583)$. For all movements, $R O M$ increased significantly $(p<0.001)$ from baseline to final treatment session in both groups.

The values of HBB reach in two groups were similar at baseline ( $p>0.05)$. A comparison of the normalized values of HBB reach between the groups after the treatment sessions revealed no significant difference $(p=0.295)$. However, there was a significant increase HBB reach after the treatment in both groups $(\mathrm{p}<0.001)$ (Table 2).

The FLEX-SF scores were also similar at baseline (Table 1). The FLEX-SF score increased significantly after the treatment $(\mathrm{p}<0.001)$ in both groups, and a significant difference between the groups $(\mathrm{p}<0.05)$ was observed at the end of the treatment (Table 2).

\section{DISCUSSION}

The objective of the present study was to compare two mobilization techniques, reverse distraction and Kaltenborn's end-range caudal and posterior glides with lateral distraction, in adhesive capsulitis patients. The patients were treated for 3 sessions per week for 6 weeks, and changes in pain, ROM, and functional disability were recorded before and after the intervention. No published study has compared these two techniques directly. Although some studies have evaluated the effectiveness of the reverse distraction technique along with other mobilization techniques ${ }^{24,25)}$, the effectiveness of reverse distraction alone in increasing mobility and reducing pain has not been investigated.

Most variables were comparable at baseline; however, the right arm was dominant in 13 and 12 cases in the reverse distraction group and Kaltenborn group, respectively. This small difference was found to be statistically significant. However, a one-unit change between the groups will hardly influence the result clinically. Similarly, although differences in affected arm, occupation, and minor injury history were statistically significant between the groups at baseline, they are unlikely to be important clinically as the groups were assembled randomly.

Scapular mobilization has been proven to be an effective treatment technique for improving shoulder mobility in patients with adhesive capsulitis ${ }^{30,32)}$. The corresponding studies used scapular mobilization procedures, such as superior and caudal gliding, upward and downward rotations, and distraction of the scapula from the thorax with the patient lying on the unaffected side. Surenkok et al. ${ }^{30)}$ have suggested that enhanced scapular movement may be due to disintegration and release of adhesions in the scapulothoracic muscles induced by scapular mobilization. This increased scapular movement may constitute the mechanism of improving shoulder movement. The reverse distraction technique, which was proposed by Stenvers ${ }^{17)}$ and later used by Vermeulen ${ }^{24)}$, is different from the scapular mobilization technique in that glide is applied to the scapula in the medial and downward rotation direction, along with lateral distraction at desired elevation angles to the humerus at the glenohumeral joint, with the patient lying on the unaffected side.

In this study, there was a significant improvement in pain in both groups, which is in accordance with previous studies $^{17,22,24,25)}$. A decrease in pain after joint mobilization has been attributed to various mechanisms, such as neurophysiological effects achieved by the stimulation of type II mechanoreceptors and by inhibition of type IV nociceptors ${ }^{38)}$, stimulation of Golgi tendon organ activity, and reflex inhibition of the muscle at the end of the passive joint mobilization ${ }^{39)}$. Joint mobilization decreases muscle activity, reducing muscle concentric activation, pain, and muscle tension in periarticular tissue ${ }^{40)}$.

The comparison of the two techniques revealed that the reverse distraction technique was significantly better than the Kaltenborn technique. There is presently no published study that can support and explain this finding, and further research is required in this regard.

Stenvers ${ }^{17}$ stated in a retrospective study that the glenohumeral joint capsule can be stretched both by fixing the scapula and mobilizing the humerus and by fixing the humerus and mobilizing the scapula. In biomechanical terms, it was suggested that during the movement of the humerus relative to the scapula, the scapula is not stabilized effectively. As a result, a laterally directed force is applied to the acromion and further to the clavicle to help stabilize the scapula indirectly via the sternoclavicular and acromioclavicuar joints. Furthermore, the movement of the humerus causes pain. Because of this pain, it is not possible to exert force on the glenohumeral joint capsule effectively. Thus, the movement of the humerus relative to the fixed scapula, as used in traditional gliding techniques, is not an effective mobilization method. In contrast to the first method, in reverse distraction no force is applied to the acromion in order to counteract the rotation of the scapula since the scapula is held in place by the joint capsule. The mobilizing force on the scapula is applied only to load the joint capsule, with no pain being caused. During the movement of the scapula with respect to the humerus, only the glenohumeral joint is involved, and the glenohumeral joint capsule is stretched without causing pain. Because of this mechanism, reverse distraction is a better mobilization method in terms of being less painful clinically.

In this study, active and passive abduction ROM in the frontal plane increased significantly after 18 treatment sessions in both groups, which supports the results of the studies conducted by Johnson et al., Vermeulen et al., and Stenver ${ }^{17,22,24,25)}$. This can be attributed to the following mechanical effects of mobilization on joint mobility: adhesions break up, realignment of collagen, or fiber gliding increase by specific movements that stress the capsular tissue ${ }^{41)}$. Moreover, the induced rheological changes in synovial fluid, increased exchange of fluid between synovial tissue and the cartilage matrix, and enhanced synovial fluid turnover are found to be affected by joint mobilization ${ }^{42}$. 
However, in the present study, the reverse distraction technique was found to be significantly better than the traditionally used mobilization techniques in increasing shoulder abduction mobility. It is known that patients with adhesive capsulitis may develop an alternative compensatory elevation strategy $\left.{ }^{43}, 44\right)$, in particular by using excessive scapular movement during arm elevation. Fayad et al. ${ }^{45}$ reported that there is increased scapulohumeral rhythm and scapular lateral rotation and decreased scapular protraction in patients suffering from frozen shoulder compared to those with glenohumeral osteoarthritis, with limited global arm elevation. Vermeulen et al. ${ }^{46}$ ) demonstrated that scapular lateral rotation of the arm affected by frozen shoulder occurred earlier and was larger during forward flexion, scapular abduction, and horizontal abduction to compensate for the decrease in mobility at the glenohumeral joint. This could be due to capsular adhesion that prevents external rotation and gliding of the head of the humerus under the acromion simultaneously with elevation of the humerus in several planes. Thus, the glenohumeral joint is blocked and the scapula is distracted outwards earlier by the humerus during elevation. Moreover, Lin et al. ${ }^{47)}$ noticed higher upper trapezius activity than lower trapezius activity in patients with adhesive capsulitis. They suggested that this increased trapezius muscle activity occurred to compensate limited glenohumeral motion in patients with adhesive capsulitis, resulting in abnormal scapular motion, excessive scapular elevation, and upward rotation during elevation of the arm.

Thus, it can be concluded from the above studies that scapulohumeral rhythm is altered and there is excessive elevation, upward rotation, and lateral rotation of the scapula, with the aim to compensate for the limited glenohumeral elevation, in patients with adhesive capsulitis. To restore normal glenohumeral ROM, abnormal scapular movement patterns should be corrected $^{48-50)}$.

Because of capsular restriction, glenohumeral joint mobilization applied before scapular mobilization can be very painful, and improvement in joint mobility cannot be appreciated. It is known that the glenohumeral and scapulothoracic joints are in a closed kinetic chain. Therefore, it was assumed that, if glenohumeral mobilization increases shoulder movements ${ }^{51)}$ and normalizes scapulohumeral rhythm ${ }^{52}$,53), the reverse distraction technique should improve shoulder movements as it is directed towards gliding the scapula in medial and downward rotations with the humerus distracted at varying angles of elevation and forward flexion. Thus, as positional correction of the scapula occurs with reverse distraction, there is an increase in mobility at the glenohumeral joint.

Although no difference was found between the groups in external ROM and HBB reach measured for internal rotation, these variables improved significantly in both groups after the 18 treatment sessions. This can be attributed to the fact that both techniques employed stretching of the posterior capsule, resulting in an increase of internal rotation ROM. In this study, HBB reach was used to measure internal rotation because it is particularly difficult to measure internal rotation using a goniometer with the arm in the neutral position because the abdomen prevents achieving the maximal internal rotation ${ }^{54)}$. Although this movement is complex, the method is effective and used clinically for measuring internal rotation of the shoulder joint ${ }^{55)}$. However, there are studies that demonstrate that HBB reach is not an exact measure of the range of internal rotation ${ }^{56,57)}$.

The FLEX SF scores improved significantly in both groups, with reverse distraction showing better results than the Kaltenborn technique. In accordance with published results, this study demonstrated that shoulder function gets better with improvement in scapular and shoulder movements ${ }^{58)}$. Therefore, the significant improvements in abduction mobility and pain achieved by the reverse distraction technique can correlate with functional improvement.

Clinically, reverse distraction improves abduction ranges, decreases pain, and improves functional status more effectively than conventionally used mobilization techniques in adhesive capsulitis patients. As opposed to other techniques, application of this technique was found to be painless, which allows applying greater force directed to the glenohumeral capsule, thereby achieving mobility at the glenohumeral joint easily and efficiently. Moreover, this can also be useful in positional correction of the scapula in patients with adhesive capsulitis.

The limitations of the present study are as follows. First, convenience sampling was used in this study, which limits the generalizability of the results to the entire population. Second, the duration of the treatment was relatively low, and further studies are recommended to evaluate the effect of longer treatment. Third, the study allowed all movements during daily activities, making it impossible to control for individual differences in motions. Future studies are therefore necessary, which may also involve scapular dyskinesis to investigate the effect of revere distraction on scapular positioning.

In conclusion, the present study supports the clinical use of the reverse distraction technique as a mobilization method alternative to conventionally used techniques aimed at decreasing pain and improving ROM and functional scores in patients with adhesive capsulitis.

\section{ACKNOWLEDGEMENT}

The project was full financially supported by King Saud University, through Vice Deanship of Research Chairs, Rehabilitation Research Chair. 


\section{REFERENCES}

1) Neviaser TJ: Intra-articular inflammatory diseases of the shoulder. Instr Course Lect, 1989, 38: 199-204. [Medline]

2) Aydeniz A, Gursoy S, Guney E: Which musculoskeletal complications are most frequently seen in type 2 diabetes mellitus? J Int Med Res, 2008 , 36: 505-511. [Medline] [CrossRef]

3) Bridgman JF: Periarthritis of the shoulder and diabetes mellitus. Ann Rheum Dis, 1972, 31: 69-71. [Medline] [CrossRef]

4) Lundberg J: The frozen shoulder. Clinical and radiographical observations. The effect of manipulation under general anesthesia. Structure and glycosaminoglycan content of the joint capsule. Local bone metabolism. Acta Orthop Scand, 1969, 40: 119, 1-59. [Medline] [CrossRef]

5) Pal B, Anderson J, Dick WC, et al.: Limitation of joint mobility and shoulder capsulitis in insulin- and non-insulin-dependent diabetes mellitus. Br J Rheumatol, 1986, 25: 147-151. [Medline] [CrossRef]

6) Mao CY, Jaw WC, Cheng HC: Frozen shoulder: correlation between the response to physical therapy and follow-up shoulder arthrography. Arch Phys Med Rehabil, 1997, 78: 857-859. [Medline] [CrossRef]

7) Balci N, Balci MK, Tüzüner S: Shoulder adhesive capsulitis and shoulder range of motion in type II diabetes mellitus: association with diabetic complications. J Diabetes Complications, 1999, 13: 135-140. [Medline] [CrossRef]

8) Castellarin G, Ricci M, Vedovi E, et al.: Manipulation and arthroscopy under general anesthesia and early rehabilitative treatment for frozen shoulders. Arch Phys Med Rehabil, 2004, 85: 1236-1240. [Medline] [CrossRef]

9) Fitzpatrick MJ, Powell SE, Tibone JE, et al.: The anatomy, pathology, and definitive treatment of rotator interval lesions: current concepts. Arthroscopy, 2003, 19: 70-79. [Medline] [CrossRef]

10) Neviaser JS: Arthrography of the shoulder joint: study of the findings in adhesive capsulitis of the shoulder. Study of the findings in adhesive capsulitis of the shoulder. J Bone Joint Surg Am, 1962, 44-A: 1321-1359. [Medline]

11) Ozaki J, Nakagawa Y, Sakurai G, et al.: Recalcitrant chronic adhesive capsulitis of the shoulder. Role of contracture of the coracohumeral ligament and rotator interval in pathogenesis and treatment. J Bone Joint Surg Am, 1989, 71: 1511-1515. [Medline]

12) Bulgen DY, Binder AI, Hazleman BL, et al.: Frozen shoulder: prospective clinical study with an evaluation of three treatment regimens. Ann Rheum Dis, 1984, 43: 353-360. [Medline] [CrossRef]

13) Siegel LB, Cohen NJ, Gall EP: Adhesive capsulitis: a sticky issue. Am Fam Physician, 1999, 59: 1843-1852. [Medline]

14) Cyriax J: Textbook of Orthopedic Medicine, 8th ed. London: Baillère Tindall, 1982.

15) Shaffer B, Tibone JE, Kerlan RK: Frozen shoulder. A long-term follow-up. J Bone Joint Surg Am, 1992, 74: 738-746. [Medline]

16) Nicholson GG: The effects of passive joint mobilization on pain and hypomobility associated with adhesive capsulitis of the shoulder. J Orthop Sports Phys Ther, 1985, 6: 238-246. [Medline] [CrossRef]

17) Stenvers JD: De Primaire Frozen Shoulder [doctoral thesis]. University of Groningen, Groningen, the Netherlands, 1994.

18) Do Moon G, Lim JY, Kim Y, et al.: Comparison of Maitland and Kaltenborn mobilization techniques for improving shoulder pain and range of motion in frozen shoulders. J Phys Ther Sci, 2015, 27: 1391-1395. [Medline] [CrossRef]

19) Harryman DT 2nd, Sidles JA, Clark JM, et al.: Translation of the humeral head on the glenoid with passive glenohumeral motion. J Bone Joint Surg Am, 1990, 72: 1334-1343. [Medline]

20) Roubal PJ, Dobritt D, Placzek JD: Glenohumeral gliding manipulation following interscalene brachial plexus block in patients with adhesive capsulitis. J Orthop Sports Phys Ther, 1996, 24: 66-77. [Medline] [CrossRef]

21) Placzek JD, Roubal PJ, Freeman DC, et al.: Long-term effectiveness of translational manipulation for adhesive capsulitis. Clin Orthop Relat Res, 1998, (356): 181-191. [Medline] [CrossRef]

22) Johnson AJ, Godges JJ, Zimmerman GJ, et al.: The effect of anterior versus posterior glide joint mobilization on external rotation range of motion in patients with shoulder adhesive capsulitis. J Orthop Sports Phys Ther, 2007, 37: 88-99. [Medline] [CrossRef]

23) Sarkari E, Dhakshinamoorthy P, Multani NK: Comparison of caudal and antero-posterior glide mobilisation for the improvement of abduction range of motion. J Exerc Sci Physiother, 2006, 2: 59.

24) Vermeulen HM, Obermann WR, Burger BJ, et al.: End-range mobilization techniques in adhesive capsulitis of the shoulder joint: a multiple-subject case report. Phys Ther, 2000, 80: 1204-1213. [Medline]

25) Vermeulen HM, Rozing PM, Obermann WR, et al.: Comparison of high-grade and low-grade mobilization techniques in the management of adhesive capsulitis of the shoulder: randomized controlled trial. Phys Ther, 2006, 86: 355-368. [Medline]

26) Ferraz MB, Quaresma MR, Aquino LR, et al.: Reliability of pain scales in the assessment of literate and illiterate patients with rheumatoid arthritis. J Rheumatol, 1990, 17: 1022-1024. [Medline]

27) Hawker GA, Mian S, Kendzerska T, et al.: Measures of adult pain: visual analog scale for pain (vas pain), numeric rating scale for pain (nrs pain), mcgill pain questionnaire (mpq), short-form mcgill pain questionnaire (sf-mpq), chronic pain grade scale (cpgs), short form-36 bodily pain scale (sf-36 bps), and measure of intermittent and constant osteoarthritis pain (icoap). Arthritis Care Res (Hoboken), 2011, 63: S240-S252. [Medline] [CrossRef]

28) Burrows H: Joint motion: method of measuring and recording. American Academy of Orthopaedic Surgeons, 1965.

29) Riddle DL, Rothstein JM, Lamb RL: Goniometric reliability in a clinical setting. Shoulder measurements. Phys Ther, 1987, 67: 668-673. [Medline]

30) Surenkok O, Aytar A, Baltaci G: Acute effects of scapular mobilization in shoulder dysfunction: a double-blind randomized placebo-controlled trial. J Sport Rehabil, 2009, 18: 493-501. [Medline] [CrossRef]

31) Sharma SP, Bærheim A, KvÅle A: Passive range of motion in patients with adhesive shoulder capsulitis, an intertester reliability study over eight weeks. BMC Musculoskelet Disord, 2015, 16: 37. [Medline] [CrossRef]

32) Yang JL, Jan $\mathrm{MH}$, Chang CW, et al.: Effectiveness of the end-range mobilization and scapular mobilization approach in a subgroup of subjects with frozen shoulder syndrome: a randomized control trial. Man Ther, 2012, 17: 47-52. [Medline] [CrossRef]

33) Cook KF, Roddey TS, Gartsman GM, et al.: Development and psychometric evaluation of the Flexilevel Scale of Shoulder Function. Med Care, 2003, 41: 823-835. [Medline] [CrossRef] 
34) Kaltenborn FM: Manual therapy of the extremity joints. Oslo: Olaf Norlis, Bokhandel, 1973.

35) Codman EA: The shoulder: rupture of the supraspinatus tendon and other lesions in or about the subacromial bursa. Boston: Thomas Todd, 1934.

36) Griggs SM, Ahn A, Green A: Idiopathic adhesive capsulitis. A prospective functional outcome study of nonoperative treatment. J Bone Joint Surg Am, 2000, 82-A: 1398-1407. [Medline]

37) Kelley MJ, McClure PW, Leggin BG: Frozen shoulder: evidence and a proposed model guiding rehabilitation. J Orthop Sports Phys Ther, 2009, 39: 135-148. [Medline] [CrossRef]

38) Mangus BC, Hoffman LA, Hoffman MA, et al.: Basic principles of extremity joint mobilization using a Kaltenborn approach. J Sport Rehabil, 2002, 11: 235-250. [CrossRef]

39) Lundberg A, Malmgren K, Schomburg ED: Role of joint afferents in motor control exemplified by effects on reflex pathways from Ib afferents. J Physiol, 1978, 284: 327-343. [Medline] [CrossRef]

40) Zusman M: Spinal manipulative therapy: review of some proposed mechanisms, and a new hypothesis. Aust J Physiother, 1986, 32: 89-99. [Medline] [CrossRef]

41) Frank C, Akeson WH, Woo SL, et al.: Physiology and therapeutic value of passive joint motion. Clin Orthop Relat Res, 1984, (185): 113-125. [Medline]

42) Noël G, Verbruggen LA, Barbaix E, et al.: Adding compression to mobilization in a rehabilitation program after knee surgery. A preliminary clinical observational study. Man Ther, 2000, 5: 102-107. [Medline] [CrossRef]

43) Cirstea MC, Levin MF: Compensatory strategies for reaching in stroke. Brain, 2000, 123: 940-953. [Medline] [CrossRef]

44) Roby-Brami A, Feydy A, Combeaud M, et al.: Motor compensation and recovery for reaching in stroke patients. Acta Neurol Scand, 2003, 107: 369-381. [Medline] [CrossRef]

45) Fayad F, Roby-Brami A, Yazbeck C, et al.: Three-dimensional scapular kinematics and scapulohumeral rhythm in patients with glenohumeral osteoarthritis or frozen shoulder. J Biomech, 2008, 41: 326-332. [Medline] [CrossRef]

46) Vermeulen HM, Stokdijk M, Eilers PH, et al.: Measurement of three dimensional shoulder movement patterns with an electromagnetic tracking device in patients with a frozen shoulder. Ann Rheum Dis, 2002, 61: 115-120. [Medline] [CrossRef]

47) Lin JJ, Wu YT, Wang SF, et al.: Trapezius muscle imbalance in individuals suffering from frozen shoulder syndrome. Clin Rheumatol, 2005, 24: 569-575. [Medline] [CrossRef]

48) Thomas SJ, McDougall C, Brown ID, et al.: Prevalence of symptoms and signs of shoulder problems in people with diabetes mellitus. J Shoulder Elbow Surg, 2007, 16: 748-751. [Medline] [CrossRef]

49) DePalma AF: The classic. Loss of scapulohumeral motion (frozen shoulder). Ann Surg. 1952; 135: 193-204. Clin Orthop Relat Res, 2008, 466: 552-560. [Medline]

50) Hallaceli H, Cimbız A, Cavlak U, et al.: Ranges of scapular elevation and depression in healthy male subjects. Eklem Hastalik Cerrahisi, 2006 , 17 : 85-88.

51) Teys P, Bisset L, Vicenzino B: The initial effects of a Mulligan's mobilization with movement technique on range of movement and pressure pain threshold in pain-limited shoulders. Man Ther, 2008, 13: 37-42. [Medline] [CrossRef]

52) Kibler WB, McMullen J: Scapular dyskinesis and its relation to shoulder pain. J Am Acad Orthop Surg, 2003, 11: 142-151. [Medline] [CrossRef]

53) Yang JL, Chang CW, Chen SY, et al.: Mobilization techniques in subjects with frozen shoulder syndrome: randomized multiple-treatment trial. Phys Ther, 2007, 87: 1307-1315. [Medline] [CrossRef]

54) Han SH, Oh KS, Han KJ, et al.: Accuracy of measuring tape and vertebral-level methods to determine shoulder internal rotation. Clin Orthop Relat Res, 2012, 470: 562-566. [Medline] [CrossRef]

55) Green S, Buchbinder R, Forbes A, et al.: A standardized protocol for measurement of range of movement of the shoulder using the Plurimeter-V inclinometer and assessment of its intrarater and interrater reliability. Arthritis Care Res, 1998, 11: 43-52. [Medline] [CrossRef]

56) Ginn KA, Cohen ML, Herbert RD: Does hand-behind-back range of motion accurately reflect shoulder internal rotation? J Shoulder Elbow Surg, 2006, 15: 311-314. [Medline] [CrossRef]

57) Wakabayashi I, Itoi E, Minagawa H, et al.: Does reaching the back reflect the actual internal rotation of the shoulder? J Shoulder Elbow Surg, 2006, 15 : 306-310. [Medline] [CrossRef]

58) Bekkering WP, ten Cate R, van Suijlekom-Smit LW, et al.: The relationship between impairments in joint function and disabilities in independent function in children with systemic juvenile idiopathic arthritis. J Rheumatol, 2001, 28: 1099-1105. [Medline] 